\title{
VARIABILIDADE GENÉTICA EM CARACTERES MORFOLÓGICOS DE POPULAÇÕES DE PLANTAS JOVENS DE ACEROLA ${ }^{1}$
}

\author{
JOÃO RODRIGUES DE PAIVA², JOSÉ JAIME VASCONCELOS CAVALCANTI ${ }^{3}$, HASSAN SABRY NETO ${ }^{4}$, \\ AMANDA SORAYA MOREIRA FREITAS ${ }^{4}$, FERNANDO HENRIQUE LIMA SOUSA ${ }^{4}$
}

\begin{abstract}
RESUMO - Com o objetivo de estimar e interpretar geneticamente a porção de variabilidade genética existente em populações de plantas juvenis de acerola obtidas de sementes, originadas de populações submetidas a processo de seleção, foi instalado um experimento com três tipos de populações, em blocos ao acaso, com 45 progênies, três repetições e número variável de 4 a 6 plantas por parcela. Tendo em vista os resultados obtidos, conclui-se que a avaliação da variabilidade genética em populações de plantas jovens de aceroleira não se constitui em material adequado para esse tipo de estudo. Também não foi possível fazer uma interpretação genética da porção de variabilidade existente nas populações, haja vista não seguirem um padrão que possibilitasse estabelecer associações entre as populações nas condições em que o trabalho foi desenvolvido.
\end{abstract}

Termos para indexação: Malpighia emarginata, população segregante, variação genética.

\section{GENETIC VARIABILITY OF MORPHOLOGICAL CHARACTERS IN YOUNG POPULATIONS OF ACEROLA}

\begin{abstract}
Aiming to estimate and to interpret the role of genetic variability occuring in sexually propagated young populations of acerola, originated from selected populations, an experiment was set up with three different populations. The experiment was conducted at the Experimental Station of the Embrapa Agroindústria Tropical, in Pacajus county, state of Ceará (Brazil). The experimental design was a randomized blocks, with 45 progenies, 3 replicates and 4 to 6 plants per plot. Results revealed that the evaluation of genetic variability in young acerola populations is not an adequate tool for the improvement of this species. Besides, it was not possible to interpret the genetic variability occurring in these populations due to the absence of a clear pattern capable of establish correlation between the populations studied. Additional test are recommended with bigger samples of progenies per population and higher number of plants per progeny in order to confirm these results.
\end{abstract}

Index terms: Malpighia emarginata, genetic variability, segregated population.

\section{INTRODUÇÃO}

Com o crescente interesse internacional no produto acerola por parte de consumidores, industriais e exportadores, devido ao seu alto teor de vitamina $\mathrm{C}$, seu cultivo intensificouse rapidamente no Brasil, no período de 1988 a 1992, principalmente pela adaptação da planta ao clima tropical e ao subtropical.

Por outro lado, as pesquisas com a espécie não cresceram na mesma proporção, principalmente aquelas que dão suporte ao melhoramento genético. Mais recentemente, tem-se dado maior ênfase em conhecer os parâmetros que auxiliam a identificação de indivíduos mais promissores, tais como: a magnitude e a natureza das variâncias genéticas que influenciam o valor fenotípico de um indivíduo; a porcentagem de variância genética que contribui para o ganho genético, através da determinação do coeficiente de herdabilidade; e a partir de marcadores moleculares, a estimação da taxa de cruzamento natural em famílias de polinização aberta (Gonzaga Neto \& Matiuz, 1999; Lopes, 1999; Oliveira et al., 1998; Paiva et al., 1999a; 1999b).
O presente trabalho visa a estimar e interpretar geneticamente a porção de variabilidade genética existente em populações de plantas juvenis de acerola obtidas de sementes, originadas de populações submetidas a processo de seleção.

\section{MATERIAL E MÉTODOS}

$\mathrm{O}$ experimento foi instalado em área da Estação Experimental de Pacajus, pertencente à Embrapa - Centro Nacional de Pesquisa da Agroindústria Tropical (CNPAT), localizada no município de Pacajus-CE, a $4^{\circ} 10^{\prime} \mathrm{S}$ e $38^{\circ} 27^{\prime} \mathrm{W}$, com altitude de $60 \mathrm{~m}$ acima do nível do mar.

O material utilizado constou de sementes de acerola que foram reunidas em populações, conforme segue: PS (população selecionada) - formada a partir de sementes de plantas selecionadas no plantio comercial da FRUCESA - Frutas do Ceará S/A, de uma amostra de 50 a 100 frutos de cada planta; PM (população melhorada) - constituída de sementes de progênies de polinização aberta formadas a partir de plantas selecionadas, a partir de uma amostra de 30 a 60 frutos por

1 Trabalho ${ }^{\circ}$ 102/2000. Recebido: 16/06/2000. Aceito para publicação: 27/06/2001. Realizado com suporte financeiro do Banco do Nordeste.

2 Eng. Agr., Dr., Embrapa Agroindústria Tropical, Caixa Postal 3761, CEP 60511-110 Fortaleza, CE.

3 Eng. Agr., M.Sc. Embrapa Agroindústria Tropical.

4 Eng. Agr., B.Sc., Bolsistas do CNPq. 
progênie; e MP (mistura de populações) - população formada pela análise dos dados reunidos das duas populações anteriores. Após a colheita, foi feito o despolpamento dos frutos e as sementes foram secas à sombra. A semeadura foi feita em setembro e o transplante para os sacos em novembro/98.

$\mathrm{O}$ experimento foi instalado em blocos ao acaso com 45 tratamentos (MP - mistura das duas populações), sendo 10 progênies da população PS e 35 da população PM, três repetições e número variável de quatro a seis plantas por parcela. A avaliação das plantas foi realizada na fase juvenil, com quatro meses de idade, mensurando-se os seguintes caracteres: altura da planta, diâmetro do caule a $5 \mathrm{~cm}$ do solo, número de ramos laterais $\mathrm{e}$ altura do primeiro ramo. $\mathrm{Na}$ análise dos dados para o caráter número de ramos, foi utilizada a transformação $\sqrt{x+0,5}$.

Para a estimação dos parâmetros genéticos, foram utilizadas as seguintes expressões, conforme Cruz (1997): $\sigma 2_{\mathrm{p}}=$ $(\mathrm{QMp}-\mathrm{QMe}) / \mathrm{rn} ; \sigma 2_{\mathrm{e}}=(\mathrm{QMe}-\mathrm{QMd}) / \mathrm{r} ; \sigma 2_{\mathrm{d}}=\mathrm{QMd} \sigma 2_{\mathrm{F}}=\mathrm{QMT}^{\mathrm{p}}$ $/ \mathrm{rn} ; \mathrm{h}^{2}=\sigma 2_{\mathrm{p}} / \sigma 2_{\mathrm{F}} ; \mathrm{CV}_{\mathrm{g}}=\left(100 . \sqrt{\sigma_{p}^{2}} / \mathrm{m} ; \mathrm{CV}=(100 . \sqrt{Q M \partial} / \mathrm{m} ;\right.$ $\mathrm{b}=\mathrm{CV}_{\mathrm{g}} / \mathrm{CV}$. Sendo $\sigma_{\mathrm{p}}^{2}$ - variância genética entre progênies; $\sigma_{e}^{2}{ }^{-}$ variância devido às diferenças ambientais entre progênies; $\sigma_{d}^{2}$ - variância fenotípica dentro de progênies; $\sigma_{F}^{2}$ - variância fenotípica entre médias de progênies; QMT - quadrado médio de tratamento; $r$ - número de repetições; $\bar{h}$-média harmônica do número de plantas por parcela; $\mathrm{m}$ - média geral do caráter; $\mathrm{h}^{2}$ - coeficiente de herdabilidade ao nível de média de progênie; $\mathrm{CV}_{\mathrm{g}}$ - coeficiente de variação genética entre progênies; $\mathrm{CV}^{\mathrm{g}}$ - coeficiente de variação experimental; b - relação entre o $\mathrm{CV}_{\mathrm{g}}$ e o $\mathrm{CV}$ experimental; $\mathrm{QMp}$ = quadrado médio entre progênies; $\mathrm{QMe}=$ quadrado médio do erro entre parcelas; $\mathrm{QMd}=$ quadrado médio dentro de progênies.

\section{RESULTADOS E DISCUSSÃO}

Os valores obtidos para o peso de uma amostra de 100 sementes por progênies da população selecionada variaram de 2,76g (progênie PS 73) a 5,79g (progênie PS 55), com média de $4,00 \mathrm{~g}$ e desvio padrão de 0,88 , enquanto que para a população melhorada a variação foi de $3,47 \mathrm{~g}$ (PM 64) a 6,58g (PM 56), com média de $4,70 \mathrm{~g}$ e desvio-padrão de 0,71 . Como se pode observar, as progênies da população melhorada possuem sementes mais pesadas e menor variação no peso da amostra de 100 sementes, em relação às progênies da população selecionada. Quanto à germinação de sementes na população selecionada, a percentagem variou de $1,6 \%$ a $15,2 \%$, enquanto, na população melhorada, a variação foi de $4,1 \%$ a $20,6 \%$.

Os quadrados médios da análise de variância para todos os caracteres estão apresentados na Tabela 1. Foram detectadas diferenças significativas entre progênies ao nível de 0,01 e 0,05 de probabilidade para todos os caracteres nas três populações, com exceção do caráter altura do primeiro ramo, indicando que, já nos primeiros quatro meses de idade, as progênies mostram comportamento diferencial para altura de planta, diâmetro do caule e número de ramos. Os valores dos coeficientes de variação experimental mantiveram-se em níveis relativamente elevados para os caracteres de altura de planta e diâmetro de caule, quando comparados com aqueles apresentados por Paiva et al. (1999c). Para altura do primeiro ramo, os valores também podem ser considerados elevados nas três populações.

As estimativas da variância genética entre progênies, para altura de planta e diâmetro do caule, foram maiores para a população melhorada, seguida da mistura de populações e da população selecionada (Tabela 2). Por outro lado, as estimativas para os caracteres altura do primeiro ramo e número de ramos seguiram padrões diferentes, ou seja, foram maiores para a população selecionada. A variação fenotípica dentro de progênies para todos os caracteres foram superiores para a população melhorada, seguida da mistura das populações e da população selecionada. Para a variância fenotípica entre médias de progênies, o padrão de distribuição também foi o mesmo, com exceção do caráter número de ramos, onde a maior variância foi detectada na população selecionada.

Normalmente, é esperado encontrar maior variância genética e menor média na população que será submetida ao processo seletivo (população original), enquanto, na população melhorada, são as esperadas menor variância genética e maior média dos caracteres (Allard, 1971). A obtenção desses resultados pode ser explicada, admitindo-se que as sementes obtidas para a formação da população melhorada, tenham sido originadas da recombinação natural dessas progênies, visto que $\mathrm{a}$ área de plantio das plantas-matrizes ficava isolada de outros plantios, proporcionando a ampliação da variabilidade genética nesta população.

Os coeficientes de herdabilidades em nível de média de progênie para todos os caracteres, nas três populações (Tabela 2), apresentaram valores considerados de médios a baixos, variando de $17,9 \%$ para o caráter altura do primeiro ramo, na mistura das populações, a $54,5 \%$ para o número de ramos na população selecionada. Em contrapartida, o coeficiente de variação genética para todos os caracteres variou de $1,85 \%$ a $5,84 \%$, enquanto que o índice ' $b$ ' se manteve relativamente baixo, variando de 0,06 a 0,28 (Tabela 2). Estes resultados mostram uma condição desfavorável à seleção.

\section{CONCLUSÕES}

1. Pelas estimativas do peso de 100 sementes, da variação do peso e da percentagem de germinação das sementes na população melhorada, conclui-se que a seleção de plantas foi eficiente na melhoria desses caracteres.

2. Para as condições em que o trabalho foi realizado, conclui-se que a avaliação da variabilidade genética em populações de plantas de aceroleira, na fase de mudas em viveiro, não se constitui em material adequado para esse tipo de estudo.

\section{REFERÊNCIAS BIBLIOGRÁFICAS}

ALLARD, R.W. Princípios de melhoramento genético de plantas. São Paulo, SP: Edgard Blucker, 1971. 381p.

GONZAGA NETO, L.; MATIUZ, B. Caracterização agronômica de clones de aceroleira (Malpighia spp) na região do submédio São Francisco. Revista Brasileira de Fruticultura, Cruz das Almas, v.21, n.2, p.110-115, 1999.

LOPES, R. Polimorfismo, sistema de acasalamento, polinizações, repetibilidade de características do fruto e avaliação de genótipos de aceroleira (Malpighia emarginata 
DC.). 1999. 146f. Dissertação (Mestrado em Genética e Melhoramento) - Universidade Federal de Viçosa, 1999.

OLIVEIRA, J.R.P.; SOARES FILHO, W.S.; CUNHA, R.B. da. A cultura da acerola no Brasil. Cruz das Almas, BA: EMBRAPA-CNPMF, 1998. 35p. ( Documentos, 85).

PAIVA, J.R.; ALVES, R.E.; CORREA, M.P.F.; FREIRE, F.C.O; SOBRINHO, R.B.; JUCÁ, W. Seleção massal de acerola (Malpighia spp.) em plantio comercial. Pesquisa Agropecuária Brasileira, Brasília, v.34, n.3, p.505-511, 1999a.
PAIVA, J.R.; ALVES, R.E.; ALMEIDA, A.S.; CORDEIRO, E.R.; PINTO, S.A.A. Características qualitativas dos frutos de progênies de polinização livre de acerola. In: CONGRESSO BRASILEIRO DE GENÉTICA. 45., 1999. Gramado, RS. Anais... Gramado: SBG, 1999b. p. 685.

PAIVA, J.R.; PAIVA, W. O.; Cordeiro, E.R.; Sabry Neto, H. Parâmetros genéticos em progênies de acerola (Malpighia spp ) de polinização livre. Pesquisa Agropecuária Brasileira, Brasília, v.34, n.4, p.629-634, 1999c. 